\title{
BILATERAL TESSIER CLEFT 3: A CASE REPORT
}

Utpal Bordoloi ${ }^{1}$

\section{HOW TO CITE THIS ARTICLE:}

Utpal Bordoloi. "Bilateral Tessier Cleft 3: A Case Report". Journal of Evolution of Medical and Dental Sciences 2014; Vol. 3, Issue 25, June 23; Page: 6852-6855, DOI: 10.14260/jemds/2014/2827

INTRODUCTION: Tessier cleft 3 is a very rare congenital anomaly,(2) especially the bilateral form. Very few cases have been reported worldwide.(1,2) I report a case of bilateral Tessier cleft 3 presenting at the age of three months with clefts extending from philtral regions, undermining the nasal alar bases to the medial canthal areas bilaterally. There were bilateral complete alveolar clefts with mild protrusion of the pre-maxilla, but the rest of the maxilla including the palate was not involved. Surgical correction was started at the age of three months and completed at the age of one and half years in three stages. There was no intra-operative or postoperative complications and the final result was satisfactory.

CASE HISTORY: A three months old female baby presented with bilateral facial clefts. The clefts were extending from philtral regions upwards undermining the alar bases to the medial canthal areas bilaterally, medial to the punctums. There were bilateral alveolar clefts with mild protrusion of the pre-maxilla. The prolabium was very small. Rest of the maxilla including the palate and orbital floor was intact. The distance between the medial canthus and the nasal ala was grossly reduced bilaterally. The naso-lacrimal duct systems were disrupted and both the punctums were blocked. There was downwards and lateral displacement of the punctums with mild ectropion of the lower eye lids, more in the left side with exposure of the cornea. There were no other congenital anomalies clinically and the general health of the baby was satisfactory. There was no suggestive maternal or family history.

The repair ${ }^{(3,4)}$ was planned in multiple stages and the left side was operated first. An incision was made along the junction of the lower eyelid and the cheek with a small back cut to raise the lower eyelid with the punctum to the medial canthal region.(5). A triangular flap(5) raised from the medial side of upper eyelid and lateral wall of nose was transposed to cover the defect thus produced. The soft tissue of the cheek and malar area was undermined and advanced medially. The nasal ala was released and pulled downwards with a back cut and the fibrotic lacrimal(2,6) duct system was excised. A tension free repair was achieved. A vermillion turn-down flap from the lateral lip element was used to form the prolabial vermillion.(5)

A similar procedure was performed in the right side after three months. However, there was complete dehiscence of the lip repair in the right side with partial dehiscence of the canthopexies. Corneal exposure was not present. The baby was operated again at the age of one and half years for repair of the lower eyelids and the lip. There were no other post-operative complications and the facial appearance at the age of two years was satisfactory.

DISCUSSION: Tessier cleft No. 3 is a well-known entity. $(1,2,5)$ It is also defined as naso- ocular cleft, nasomaxillary dysplasia and Oblique facial(2) cleft by various authors. The cleft lies along the region of the union of medial and lateral nasal processes with the maxillary process. Failure of fusion of the processes, failure of mesodermal penetration, failure of naso-optic groove formation are various 
explanations of the deformity.(2) The upper lip cleft is located at the same region as commonly seen cleft lip and the alveolar cleft lies between the lateral incisor and the canine tooth.(2) However, as the cleft travels north bound, it undermines the nasal alar base to the medial canthus and produce coloboma of the lower eyelid medial to the punctum.(2) The vertical distance between the base of the ala and the medial canthus is reduced.(2) The medial canthus is displaced inferiorly and the nasolacrimal duct system is disrupted.(6)

In mild form there may be coloboma of the nasal ala only. ${ }^{(4)}$ However, encephalocele, $(7,8)$ complete absence of frontal process of maxilla, orbital floor and confluence of the orbit, maxillary sinus and oral cavity can be seen in severe forms.(4) The present case had bilateral clefts. The upper lip cleft was bilateral with bilateral alveolar clefts and mildly protruded pre-maxilla. The clefts extended upwards along the alar grooves to the medial canthi bilaterally with coloboma of the lower eyelids. The rest of the maxilla including the palate, frontal bone, orbits was not involved.

Like any facial cleft surgery, correction of soft tissue defects $(3,4)$ is the primary goal of treatment. Cleft 3 represents one of the most challenging malformations for reconstruction. The 'split approach' proposed by R. K. Misra et al(5) is very useful in planning the repair. Accordingly, the repair can be divided into lid component, lip component and naso-malar component. The lower eye lid along with the punctum is released by making an incision along the junction of the lower eyelid and the cheek and attached to the medial canthal area.

The defect produced is closed by a triangular flap from the lateral nasal wall after the canthopexy. The vertical distance between the ala and the medial canthus can be corrected by a wellplanned z-plasty.(3,4,5) Wide undermining of soft tissue over maxilla and zygomatic arch should be done to achieve tension free closure. Bony defects are corrected by bone grafting.(2) The lip repair can be done in the same stage or in another stage. A back cut in the nasolabial crease is required to rotate the lateral segment downward and Veau-3 type of repair (5) for bilateral cleft lip can be followed.

\section{REFERENCES:}

1. Akoz T, Erdogen B, Gorgu M, Kutlay R, Dag F. Bilaterally involved Tessier No. 4 cleft: case report. Cleft Palate Craniofac J. 1996 May; 33 (3): 252-4.

2. Henry K. Kawamoto, Jr. Rare craniofacial clefts. Plastic Surgery. Joseph G. McCarthy. WB Saunders Company. 1990; 2927-41.

3. Goran J, Zambia. Zambia: URGENT Bilateral Cleft Face. Mhtml: file://F:\Zambia URGENT Bilateral Cleft Face.mht.

4. Dandan $\mathrm{Wu}$, Guomin Wang, Yusheng Yang, Teng wan. Severe bilateral Tessier 3 clefts in a Uighur girl: The significance and surgical repair. Journal of Cranio-Maxillo-Facial Surgery: vol: 10. 1016/j. jcms2012; 11.040.

5. R. K. Mishra and Reetesh Purwar. Fommatting the surgical management of Tessier cleft types 3 and 4. Indian J Plast Surg, 42 (Suppl): S174-S183.

6. Park SW, Kim NJ, Choung HK, Khwarg SI. Surgical Repair of Canalicular Defects and Congenital Eyelid colobomas Associated with Tessier No. 3 Cleft. J Korean Ophthalmol Soc. 2010 Nov; 51(11): 1520-1524

7. Sanchez Valle, G. S. Vasquez Ruiz, L. Ubaldo-Reyes, O. Lescas-Mendez, J. C. Mancera, A. Rojas Granados, M. A. Castellanos. Fisura facial nasoorbitaria, Tessier numero 3. Revista de la Facultad de Medicina de la UNAM. Vol. 54, N. 6. November-December 2011. 


\section{CASE REPORT}

8. Tozawa Asami, Nakaoka Hiroki, Tosuka Hisashi. A case of Craniofacial Cleft, Tessier No. 3, No. 11 Cleft, with Encephalocele. Journal of the Japan Society of Cranio-Maxillo-Facial Surgery: Vol.22; No.4; 302-307(2006).

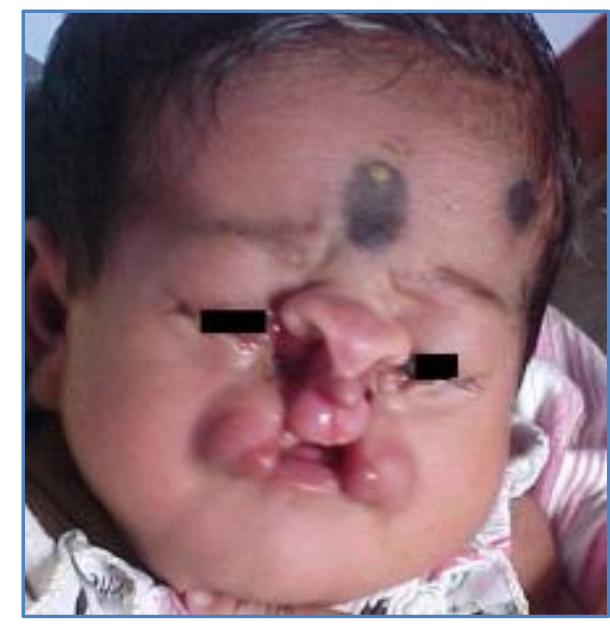

PHOTOGRAPH 1: BILATERAL TESSIER CLEFT 3 AT PRESENTATION

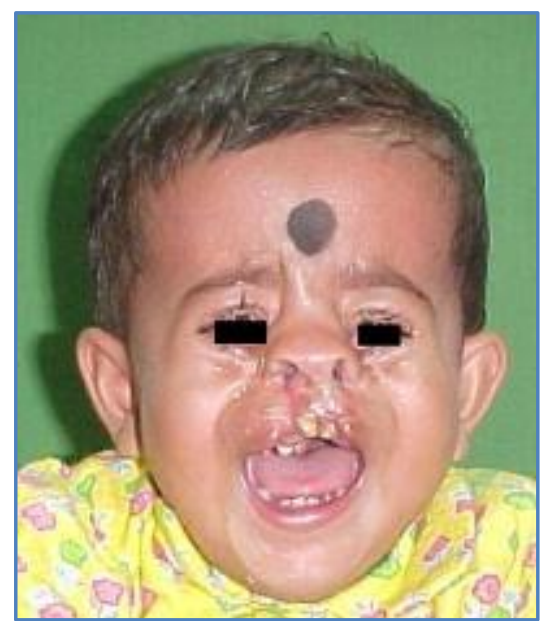

PHOTOGRAPH 3: REPAIR OF THE RIGHT SIDE WAS DONE SIMILARLY

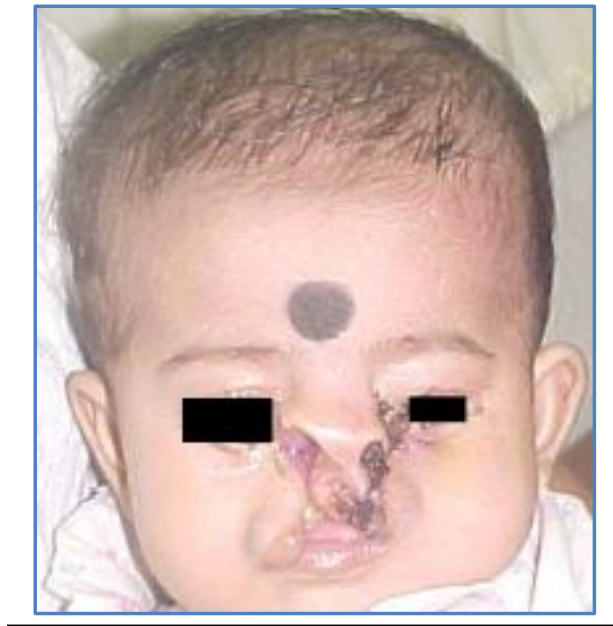

PHOTOGRAPH 2: EARLY POST OPERATIVE PHOTOGRAPH AFTER REPAIR OF THE LEFT SIDE

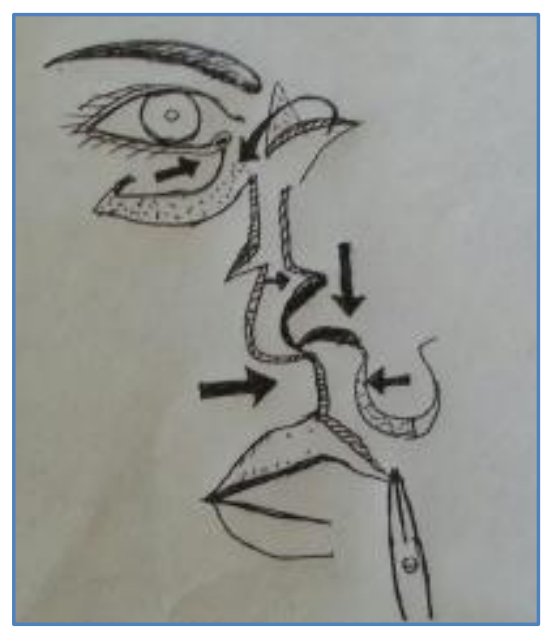

PHOTOGRAPH 4: DIAGRAMMATIC REPRESENTATION OF THE RIGHT SIDED REPAIR 


\section{CASE REPORT}

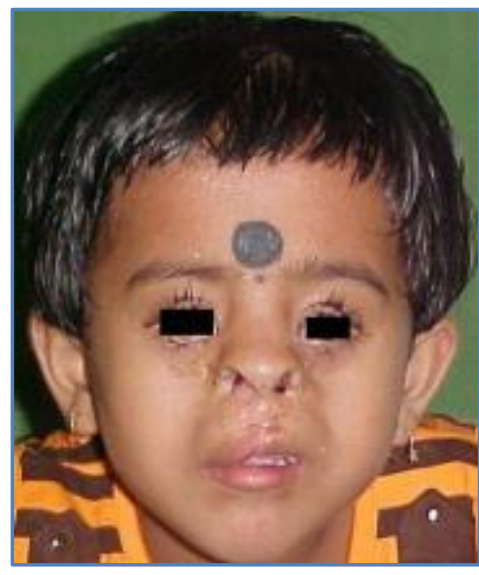

PHOTOGRAPH 5: REPAIR OF THE LIP

AND LOWER EYELID DEFECTS

\section{AUTHORS:}

1. Utpal Bordoloi

\section{PARTICULARS OF CONTRIBUTORS:}

1. Associate Professor, Department of Plastic Surgery, Assam Medical College, Dibrugarh and Consultant Plastic Surgeon, Srishti Hospital and Research Center, Dibrugarh, Assam.

\section{NAME ADDRESS EMAIL ID OF THE} CORRESPONDING AUTHOR:

Dr. Utpal Bordoloi,

Associate Professor,

Department of Plastic Surgery,

Assam Medical College, Dibrugarh.

E-mail: utpalbordoloi50@gmail.com

Date of Submission: 30/04/2014.

Date of Peer Review: 31/04/2014.

Date of Acceptance: 09/06/2014.

Date of Publishing: 17/06/2014. 